\title{
No Relationship Between Body Mass Index During Adolescence and All-Cause Mortality in Japanese Women - A 56.5-Year Observational Study
}

\author{
MUTSUMI SATO, RD, SATORU KODAMA, MD, PHD, AYUMI SUGAWARA,RD, \\ KUMIKO TOTSUKA, RD, KAZUMI SAITO, MD, PHD, and \\ HIROHITO SONE, MD, PHD, FACP
}

Department of Lifestyle Medicine, Ochanomizu University, Tokyo, Japan and Department of Internal Medicine, University of Tsukuba, Mito, Japan

Corresponding Author:

\section{Hirohito Sone, MD, PHD, FACP, Professor}

Department of Internal Medicine, University of Tsukuba Institute of Clinical Medicine, 3-2-7 Miya-machi, Mito, Ibaraki, Japan (310-0015)

Fax: +81-29-233-9960

E-mail: hsone@md.tsukuba.ac.jp 


\section{INTRODUCTION}

It is well known that the body mass index (BMI) in adulthood is closely associated with subsequent mortality regardless of ethnic group (1, 2), including Asians (1). However, the association between BMI during adolescence and subsequent mortality has not been completely established (3-5). Also, previous studies, including the above-referenced reports, (3-5) were done only in Western countries with a predominantly Caucasian population. That there are no such reports from Asian countries despite vast ethnic differences in physical size and degrees of obesity led us to examine this issue in our extremely long-term cohort of Japanese women.

\section{METHODS}

From 1947 to 56, the height and weight of all 513 students (mean age, 16.5 [standard deviation (SD) , 1.3] years) who were attending the Ochanomizu University Senior High School, a typical high school located in the Tokyo urban area, had been measured by school nurses; from this information we calculated the BMI (weight [in kilograms]/height [square meters]) of these students. Vital status of the subjects was determined through records of the school's alumni association, and the follow-up rate was 97\%. All analyses were performed by using the Statistical Package for the Social Sciences, version 15.0, for Windows (Chicago, IL).

\section{RESULTS}

A total of 513 subjects whose mean age was 16.5 years (SD, 1.3) and mean BMI was 20.2 (SD, 2.1) (range, 15.0-26.3) were followed up for a mean duration of 56.5 years (range, 3.3-61.2), comprising 29,130 person-years. Forty-three deaths occurred during the observational period. We calculated the relative risk of all-cause mortality by the Cox proportional hazard model and found that it was not significantly increased by an elevated BMI (1.01 [95\% confidence interval: 0.85, 1.19]). Also, Kaplan-Meier analysis with log-rank testing did not reveal significant differences in cumulative all-cause mortality between subjects in each tertile of BMI ( $p=0.689$; Fig. 1). Additionally, there were no 
significant differences between subjects in each half, quartile, and quintile of BMI (data not shown).

\section{DISCUSSION}

Our results demonstrated that an elevated BMI in Asian female adolescents was not associated with long-term all-cause mortality. This result differs from studies of Caucasians that concluded that a high BMI in adolescence is predictive of adult mortality, such as reported by Engeland et al. and Hoffmans et al. (3, 5, respectively). The reasons for this difference in results are currently unclear; however, Asians in general have a lower BMI (6) but a higher percentage of body fat. Differences in distribution of body fat (7) exist between Asians and Caucasians, which might influence the impact of BMI on morbidity and mortality.

In terms of historical background of our cohort, the year 1947, when our cohort was formed, was during the immediate post-war period in Japan so the influence of this historical background needs to be considered. Our subjects included those over a rather long period from 1947-1956; thus, not all were living under conditions of deprivation and hardship. Actually, the mean BMI of Japanese women aged 17 years has remained consistently constant, at around 21, during the approximately 60-year period of the follow-up (8). Therefore deprivation or hardship had little influence on BMI in our subjects.

In addition, although the survival rate of our cohort, which was $91.6 \%$, appears very high, it is quite close to that of age-matched Japanese women in the general population, which was reported to be $85.5 \%$ (9). These high survival rates for Japanese elderly women are quite normal, since Japanese women have the longest life expectancy in the world.

Although the number of subjects in our cohort was relatively small and only women attended the Ochanomizu University Senior High School, our observational period was 56.5 years, which was longer than in previous studies (3-5). Moreover, the follow-up rate of 97\% was extremely high, considering the long follow-up period. Further investigations with longer observational periods from many ethnic groups might be 
necessary before we can conclude that a high BMI in adolescence is predictive of longevity. Such a conclusion could have a profound psychological effect, such as leading to a depressive status or high-risk behavior among adolescents (10). Our current results demonstrated that a higher BMI in adolescence was not associated with long-term all-cause mortality. Therefore, we think that we should not put too much pressure on young people who are at their most sensitive stage in life to achieve what is considered a healthful and ideal weight.

ACKNOWLEDGMENT: This study is a part of the Ochanomizu Alumnae Health Study (OAHS). Emiko Suzuki, PhD, at the Ochanomizu University, Kazuko Sakurai, Toshiko Kobayashi, Yoko Nakatani, Syoko Oshita, staff and member (all from SAKURAKAI, the alumni association of Ochanomizu University Senior High School), Kazuhiko Murooka, Hajime Nagano, Tomoko Ishii, Kayano Masuda (all from Ochanomizu University Senior High School) provided assistance with the acquisition of the data. This work was supported in part by Japanese Ministry of Health, Labor and Welfare, Japan Society for the Promotion of Science (JSPS), and the Takeda Science Foundation.

\section{REFERENCES}

1. Jee SH, Sull JW, Park J, Lee SY, Ohrr H, Guallar E, et al. Body-mass index and mortality in Korean men and women. N Engl J Med. 2006; 355: 779-787.

2. Flegal KM, Graubard BI, Williamson DF, Gail MH. Excess deaths associated with underweight, overweight, and obesity. JAMA. 2005; 293: 1861-1867.

3. Engeland A, Bjorge T, Sogaard AJ, Tverdal A. Body mass index in adolescence in relation to total mortality: 32-year follow-up of 227,000 Norwegian boys and girls. Am J Epidemiol. 2003; 157: 517-523.

4. Lawlor DA, Martin RM, Gunnell D, Galobardes B, Ebrahim S, Sandhu J, et al. Association of body mass index measured in childhood, adolescence, and young adulthood with risk of ischemic heart disease and stroke: findings from 3 historical cohort studies. Am J Clin Nutr. 2006; 83: 767-773.

5. Hoffmans MD, Kromhout D, de Lezenne Coulander C. The impact of body mass 
index of 78,612 18-year old Dutch men on 32-year mortality from all causes. J Clin Epidemiol. 1988; 41: 749-756.

6. Wang J, Thornton JC, Russell M, Burastero S, Heymsfield S, Pierson RN Jr. Asians have lower body mass index (BMI) but higher percent body fat than do whites: comparisons of anthropometric measurements. Am J Clin Nutr. 1994; 60: 23-28.

7. He Q, Horlick M, Thornton J, Wang J, Pierson RN Jr., Heshka S, et al. Sex and race differences in fat distribution among Asian, African-American, and Caucasian prepubertal children. J Clin Endocrinol Metab. 2002; 87: 2164-2170.

8. Ministry of Education, Culture, Sports, Sceience and Technology. Physical Development of Students (Female). Available at: http://www.mext.go.jp/english/statist/index16.htm. Accessed Feb. 9, 2009.

9. Ministry of Health, Labor, and Welfare. Survival situation in the life table. Available at: http://www.mhlw.go.jp/english/database/db-hw/lifetb06/2.html. Accessed Feb. 9, 2009. (in Japanese)

10. Strauss RS. Childhood obesity and self-esteem. Pediatrics. 2000; 105: e15. 


\section{FIGURE 1.}

Kaplan-Meier cumulative mortality curve for all-cause mortality during a long follow-up period according to the BMI level in 513 women. (Intertertile thresholds of BMI were 19.3 and 21.1)

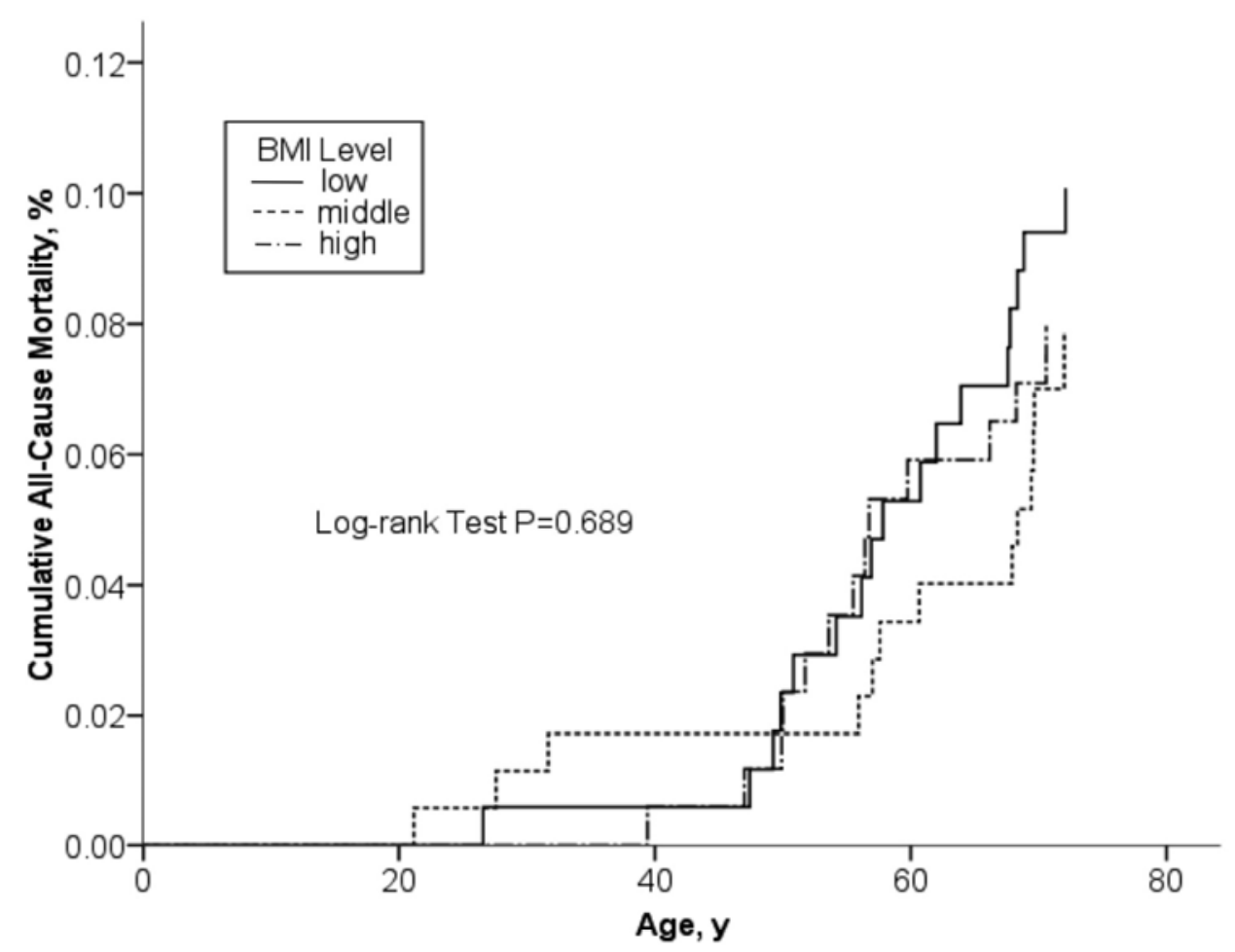

No. at Risk

$\begin{array}{llllll}\text { low } & 170 & 170 & 169 & 161 & 153 \\ \text { middle } & 174 & 174 & 171 & 168 & 161 \\ \text { high } & 169 & 169 & 168 & 159 & 156\end{array}$

